\title{
Risk Assessment in a Materials Recycling Facility: Perspectives for Reducing Operational Issues
}

\author{
Lucian Ionel Cioca $1,2, * \mathbb{1}$, Navarro Ferronato ${ }^{3}$, Paolo Viotti ${ }^{4}$, Elena Magaril ${ }^{5}\left({ }^{\circ}\right.$, Marco Ragazzi $^{6}$, \\ Vincenzo Torretta ${ }^{3}$ (i) and Elena Cristina Rada ${ }^{1,3, *}$ \\ 1 Department of Industrial Engineering and Management, Lucian Blaga University of Sibiu; 550024 Sibiu, \\ Romania \\ 2 Academy of Romanian Scientists, 010071 Bucharest, Romania \\ 3 Department of Theoretical and Applied Sciences, Insubria University, 21100 Varese, Italy; \\ navarro.ferronato@uninsubria.it (N.F.); vincenzo.torretta@uninsubria.it (V.T.) \\ 4 Department of Civil Engineering, La Sapienza University, 00184 Roma, Italy; Paolo.Viotti@uniroma1.it \\ 5 Department of Environmental Economics, Ural Federal University, 620002 Ekaterinburg, Russia; \\ magari167@mail.ru \\ 6 Department of Civil Environmental and Mechanical Engineering, University of Trento, 38123 Trento, Italy; \\ marco.ragazzi@unitn.it \\ * Correspondence: lucian.cioca@ulbsibiu.ro (L.I.C.); elena.rada@uninsubria.it (E.C.R.); \\ Tel.: +39-0461282613 (E.C.R.)
}

Received: 24 October 2018; Accepted: 6 December 2018; Published: 10 December 2018

check for updates

\begin{abstract}
Mechanical separation of light packaging waste is a useful practice for improving the quality of the recyclable waste flows and its exploitation in a frame of the circular economy. Materials Recovery Facilities can treat from 3000 to 5000 tons per year of light packaging waste. Concerning the plastic content, this is divided in four flows: PET, HDPE, other plastics, and waste rejects. The last two are generally used for energy recovery. For improving the quality of the recyclable plastic waste, a manual separation is required for reducing the impurities detectable in the final products. However, this practice could enhance the risk at work of the operators, which should be constantly monitored. This article explores the main differences of a manual separation and of a mechanical separation, assessing the costs and the health risk for the workers. The analysis started from the situation in an Italian Materials Recovery Facility, generalizing the context; a future scenario with the application of a mechanical separation is theoretically introduced. The main results obtained suggest that the manual separation plant improves the quality of the material, though increasing the risk of the operators due to the possible contact with sharp waste, sanitary danger, and risk of injuries for the mismanagement of machines, among others. The mechanical separation can be considered a real advantage from an economic point of view, since the operating costs are lower and the investment could be recovered in around 10 years, in an Italian-like context. On balance, on the one hand, the article provides indications for the private sector for improving the management of a Materials Recovery Facility, while, on the other hand, it detects the main pros and cons of both methodologies.
\end{abstract}

Keywords: circular economy; manual separation; mechanical separation; MRF; risk assessment

\section{Introduction}

Selective collection (SC) of municipal solid waste (MSW) is a priority of the European Commission (EC) in a frame of the circular economy. The recovery of the recyclable material, in particular packaging waste, has been highlighted also within the last circular economy package published in 2018 [1-3]. Thus, the implementation of integrated systems for improving the recycling rate in MSW and packaging waste increased of importance for the countries forming part the European Union (EU) [4-7]. 
North of Italy is one of the regions that achieved the highest recycling rate in Europe. Some experiences overcome $65 \%$ of SC [8]. One example is the province of Trento (about 540,000 inhabitants), which achieved $77 \%$ of SC in 2014, overcoming the disposition of the EC [9-11].

Of course, source separation, involving the citizens, is only the first step of the strategy; SC organization and operation must be performed guaranteeing quality to be checked in order to find criticalities and solution to be implemented [12,13]. The rate of recycling must be the highest possible, when compared to the SC streams. That means the presence of rejects in the SC streams must be reduced to the minimum possible. Today SC in the province of Trento has overcome $80 \%$. This result was reached thanks to:

- the application of a curbside collection of various recyclable waste (mostly plastic, paper, glass, metals and food waste);

- the implementation of collection centers for specific streams (waste from electric and electronic equipment, batteries, other plastics, green waste, among others); and

- the use of a pay-as-you-throw system, that incentives SC as demonstrated in the recent literature [14].

The residual MSW (less than $20 \%$ of MSW) is sent in part to landfilling after pre-treatment and in part to energy recovery out of the region.

However, for the application of an efficient waste SC, the implementation of Materials Recovery Facilities (MRF) is always required (in Italy their presence counts for 32 facilities [15]).

Indeed, their role is:

- to separate the rejects and impurities detectable within the waste (wood, glass, unrecyclable plastic); and

- to improve the quality of the separation of valuable materials (aluminum, PET, PE).

The application of MRFs is compulsory for enhancing the market value of the recyclable materials and for improving the quality of the recycling rate, which should not be confused with the SC rate (only a fraction of the collected stream can be valorized as material because of the presence of rejects). However, MRFs require in general the manual separation of rejects and consequently pose the operators to health risks.

The operational risk assessment is an issue that should be weighed in order to reduce the danger of injuries and illnesses due to work activities [16]. In particular, danger is defined as the property of a factor to cause damage, while risk is the probability to achieve the level of which the damage could be conditioned by a factor or agent. Thus, the main activity to be applied for reducing the risk is to decrease the probability of damage. For that purpose, some precautions could be introduced, such as the use of personal protection equipment, the control of the systems, procedures for the use of mechanical systems and the involvement of the employees $[17,18]$. Another safety measure is designing the MRFs in order to reduce the risk, as well as convincing the workers that it is better to reduce production rather than safety to maintain the system [19]. This last aspect is more important in low-income contexts. In high income contexts, as in Italy, the presence of guidelines helps in preventing injuries [20]. 
The aim of this article is to assess the risk due to the manual separation of recyclable materials at a reference MRF fed by source-separated light packaging waste, suggesting possible measures that could improve the operational safety. Lightweight packaging materials of interest for the MRF are every primary and secondary packaging, in plastic, aluminum, ferrous materials, composite materials and, finally, disposable plates and glasses (in plastic). In the reference scenario, all the materials classified as light packaging are separately collected by a colored bag. In particular, the introduction of an optical separation and a shredding system is proposed as theoretical scenario for comparing operational risks with the manual separation. Considerations about the reduction of the safety risk are provided. Moreover, the economic advantages of the mechanical system is assessed in function of the waste amount collected in the region, considering the high recycling rates achieved.

\section{Structure of the MRF}

A MRF could be based mainly on manual operations or could be mechanically advanced, in function of the mechanical systems introduced for separating the recyclable materials. In particular, the first uses mainly the manual separation, while the second considered mainly the separation by mechanical systems, such as sensors, ballistics separators, shredders and trommels. Generally, one line of a manual separation facility could treat one ton per hour, with a minimum of 12 operators, while one line of a mechanical facility could treat about three tons per hour with about 7-10 operators [21]. A parameter that can vary is the number of working cycles per day. For this kind of facilities, a common solution is one cycle per day (that means daylight operation).

The facility considered in this study, even if hypothetical, is based on the characteristics of a real scale one, conceived with the following stages:

- a bag opening system as light packaging is assumed to come in plastic bags;

- a preliminary manual separation to separate bulky waste;

- a rotating trommel aimed to separate the stream in two outputs; the over sieve is considered recyclable;

- a magnetic separator for ferrous packaging;

- $\quad$ an induced current separator aimed mainly to separate aluminum cans;

- a ballistic separator (heavy materials are assumed as rejects);

- an optic separator (separating according to polymer and color); and

- a second manual separation to support the optic separator.

The rejects are variable for the MRFs of this sector as they depends on the quality of the input and the quality of the treatment. In this article, the rejects have been assumed about $18 \%$ of the waste inflow into the facility [22]. This value can be considered as consequence of a virtuous approach. The recyclable materials finally obtained are plastics (HDPE, PVC, PS, LDPE, PET), ferrous metals and non-ferrous metals. The rejects are composed of bulky materials, black plastics, wood, and fine fractions. The manual separation is assumed to be located before the rotating trommel, after the bag opening system, and after the final optic sensor for separating the valuable fractions not detected by the optic sensors.

The facility is assumed suitable to treat up to 5000 tons of waste per year. This value positions it in the high range of capacities. The working hours are assumed $8 \mathrm{~h} /$ day, Monday-Friday, for 50 weeks per year, giving the input reported in Figure 1. Efficiencies of each step are taken from a similar MRF available in the literature [22]. 


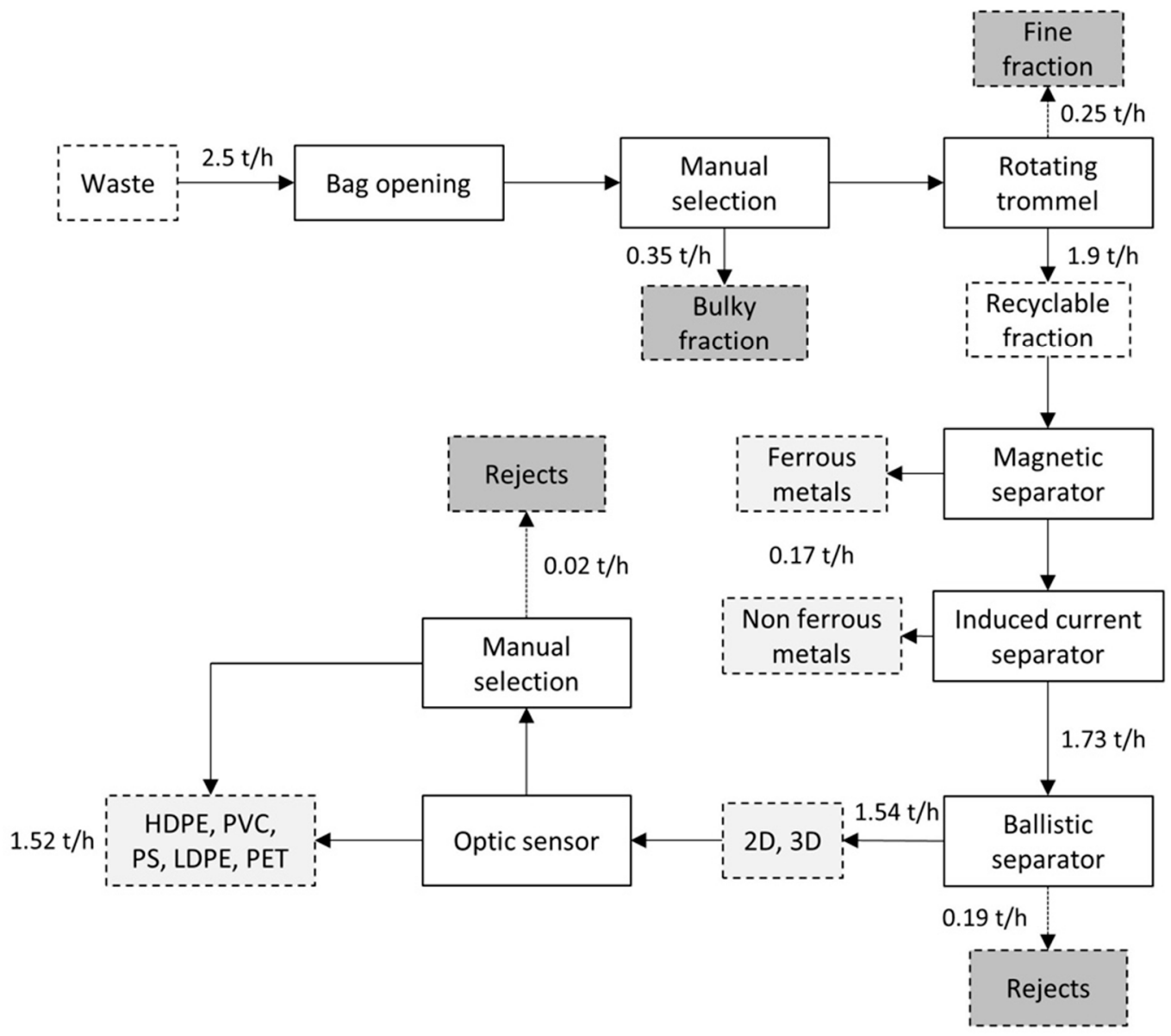

Figure 1. Waste flow treated in the MRF (fine and bulky fractions can be assumed as reject).

\section{Methods}

A theoretical scenario was introduced in order to compare possible improvements starting from the initial configuration of Figure 1. For both cases, a risk assessment can be developed, based on a matrix of risk (Table 1) crossing the probability of event for a phenomenon and the relative magnitude. The risk comes from the multiplication of the probability and the magnitude. Four classes of risk (having a different color) can be defined depending on the result of this multiplication.

Table 1. Matrix of risk.

\begin{tabular}{rrrrrc}
\hline \multicolumn{2}{r}{ Matrix of Risk } & \multicolumn{5}{c}{ Magnitude } \\
\hline \multirow{3}{*}{ Probability } & 1 & 1 & 2 & 3 & 4 \\
& 2 & 2 & 4 & 6 & 8 \\
& 3 & 3 & 6 & 9 & 12 \\
& 4 & 4 & 8 & 12 & 16 \\
\hline
\end{tabular}

Note: green = acceptable; yellow = low; orange = significant; red = high.

The objective of the evaluation are mainly two: recognize the source of danger of a manual separation or a mechanical separation and suggest a possible alternative to the manual separation. The analysis conducted considered the ordinary conditions of the facility, while the risks considered, typical of a mechanical separation are reported in Table 2 , based on a modified recognition on a facility analyzed in the literature [22]. Modifications started from the reference scheme of the facility, giving a theoretical facility as reference for this article. 
Table 2. Factors assessed for a typical plant of the sector [22].

\begin{tabular}{cl}
\hline Risks & \multicolumn{1}{c}{ Characteristics } \\
\hline Biological & $\begin{array}{l}\text { Presence of bacteria, parasites, fungus, allergies, intoxications, infections } \\
\text { and pathogens even if the material is dry. }\end{array}$ \\
\hline Chemical & $\begin{array}{l}\text { Emission of chemical compounds during the storage of waste or } \\
\text { functioning of the machines (conveyed and diffused emissions). }\end{array}$ \\
\hline Noise & $\begin{array}{l}\text { Caused by the functioning of the mechanics or machines that could affect } \\
\text { the hearing system. }\end{array}$ \\
\hline Vibrations & $\begin{array}{l}\text { Caused by the functioning of the machines and operation near mechanical } \\
\text { systems. }\end{array}$ \\
\hline Machines moving & $\begin{array}{l}\text { Due to the operation of the machines that move waste and provide it to the } \\
\text { facility. }\end{array}$ \\
\hline Falling of workers & $\begin{array}{l}\text { Mainly caused by any kind of work at high altitude, e.g., along footbridges } \\
\text { or in suspended areas. }\end{array}$ \\
\hline Falling of objects & Waste or other materials could fall down the machines. \\
\hline Cuts & $\begin{array}{l}\text { Caused by the contact with sharps materials detectable in the mixed waste } \\
\text { or by the contact with parts of the machines. }\end{array}$ \\
\hline Effort & $\begin{array}{l}\text { The work and the activities required during the process could be cause of } \\
\text { loss of attention. }\end{array}$ \\
\hline Indoor environment & $\begin{array}{l}\text { Within the facility, different climatic conditions could occur due to extreme } \\
\text { temperatures or the low quality of the air. }\end{array}$ \\
\hline Fire & $\begin{array}{l}\text { Caused by the overheating of the machineries and the presence of } \\
\text { combustible materials (specifically in the case of light packaging). }\end{array}$ \\
\hline
\end{tabular}

In order to develop the comparison, a preliminary recognition of the literature was made in order to analyses the level of details of the available information on this kind of facilities and collect useful data.

After the risk assessment, based on the methodology of reference in Italy [23], preliminary cost considerations are introduced in order to provide some considerations about the feasibility of the scenario suggested at an economic point of view.

Some consideration on a change of context completed the analysis.

\section{Results}

The literature available in this sector is often restricted because of know-how protection. This is one of the reasons of the limited amount of articles present in the international databases on this topic. Even when detailed, the most recent scientific works present generally:

- $\quad$ an overview of the sector and configurations [24,25];

- proposals for enhancement of specific steps of treatment [26]; and

- valorization of the outputs of the light packaging separation [27-29].

On the contrary, what is needed for the comparison aimed in the present article is a detailed analysis with accessible data on each step of treatment in a MRF. To this concern an accessible and detailed analysis recently developed in an Italian MRF is available [22]. In the following paragraphs and extraction and adaptation of the available analysis is presented to make the comparison between manual and mechanical separation. 


\subsection{Risks Assessment of the Manual Separation}

During manual separation, the main operations applied regard the separation of the bulky materials, the separation of the rejects after the optic separation at the end of the line, storage of the waste selected in appropriated containers, movement of the containers and clean of the areas. The risk matrix is reported in Table 3 [22]. In the original version of the table, the main risk in all the processes is the biological one, due to the continue contact with the waste, which is the main source of danger for the workers. In this version, the biological risk has been reduced always of one point as the context is assumed the one of the area of Trento, north of Italy, where the inhabitants have recently demonstrated a particular attention in source separating food waste and putrescible materials into a SC stream. By this way, the human exposure to this risk was reduced. At the same time, the risk of cuts is present during the manual separation of the material, since the waste could contain impurities and materials that are not appropriate for the separation. This is mostly valid in the first step of the manual separation, where the fractions are not separated yet, and the metals are still present. Thus, the risk could be reduced using personal protection equipment or by the substitution of the process, since the contact with the waste is unavoidable.

Table 3. Risk matrix of the manual separation system; fire risk is not present [22].

\begin{tabular}{|c|c|c|c|c|c|c|c|c|c|c|}
\hline & \multirow[b]{2}{*}{ Assessed Risk } & \multicolumn{9}{|c|}{ Risks } \\
\hline & & 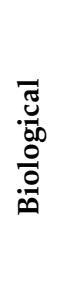 & 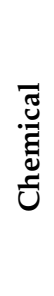 & $\begin{array}{l}\tilde{n} \\
\stackrel{0}{0} \\
\text { Z }\end{array}$ & 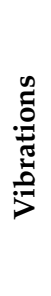 & $\begin{array}{l}\stackrel{\mathscr{\Xi}}{\Xi} \\
\stackrel{\Xi}{\Xi} \\
\sum\end{array}$ & $\stackrel{n}{\vec{J}}$ & 总 & 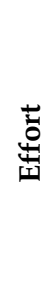 & 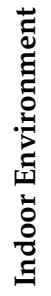 \\
\hline \multirow{5}{*}{ 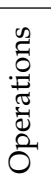 } & Manual separation & 12 & 9 & 4 & 2 & 2 & 16 & 2 & 3 & 6 \\
\hline & Waste storage & 9 & 9 & 2 & 2 & 2 & 8 & 2 & 3 & 2 \\
\hline & Manual movement of the waste & 9 & 9 & 8 & 2 & 6 & 8 & 6 & 3 & 2 \\
\hline & Mechanical movement of the waste & 6 & 6 & 4 & 4 & 4 & 4 & 2 & 6 & 2 \\
\hline & Cleaning of the area & 12 & 12 & 6 & 2 & 6 & 8 & 2 & 3 & 4 \\
\hline
\end{tabular}

Note: green = acceptable; yellow $=$ low; orange = significant; red = high.

\subsection{Risks Assessment of the Mechanical Separation}

Substituting the manual separation with a mechanical separation system, the operational risks can be reduced. In particular, the suggestion is to implement a shredding system before the trammel (Figure 2). This allows reducing the diameter of the materials, avoiding the rejection of bulky waste. In particular, the substitution is recommended since here the risk of injuries to the operators is very high, as reported in Table 3.

Again, the biological risk has been reduced of one point (but never to zero) when possible. The results of the risk assessment are reported in Table 4. It could be stated that the risk is considerably reduced in comparison with the manual separation: the substituting step of treatment has no red classified risks, differently from the manual separation approach (four cases out of 45 evaluations) 


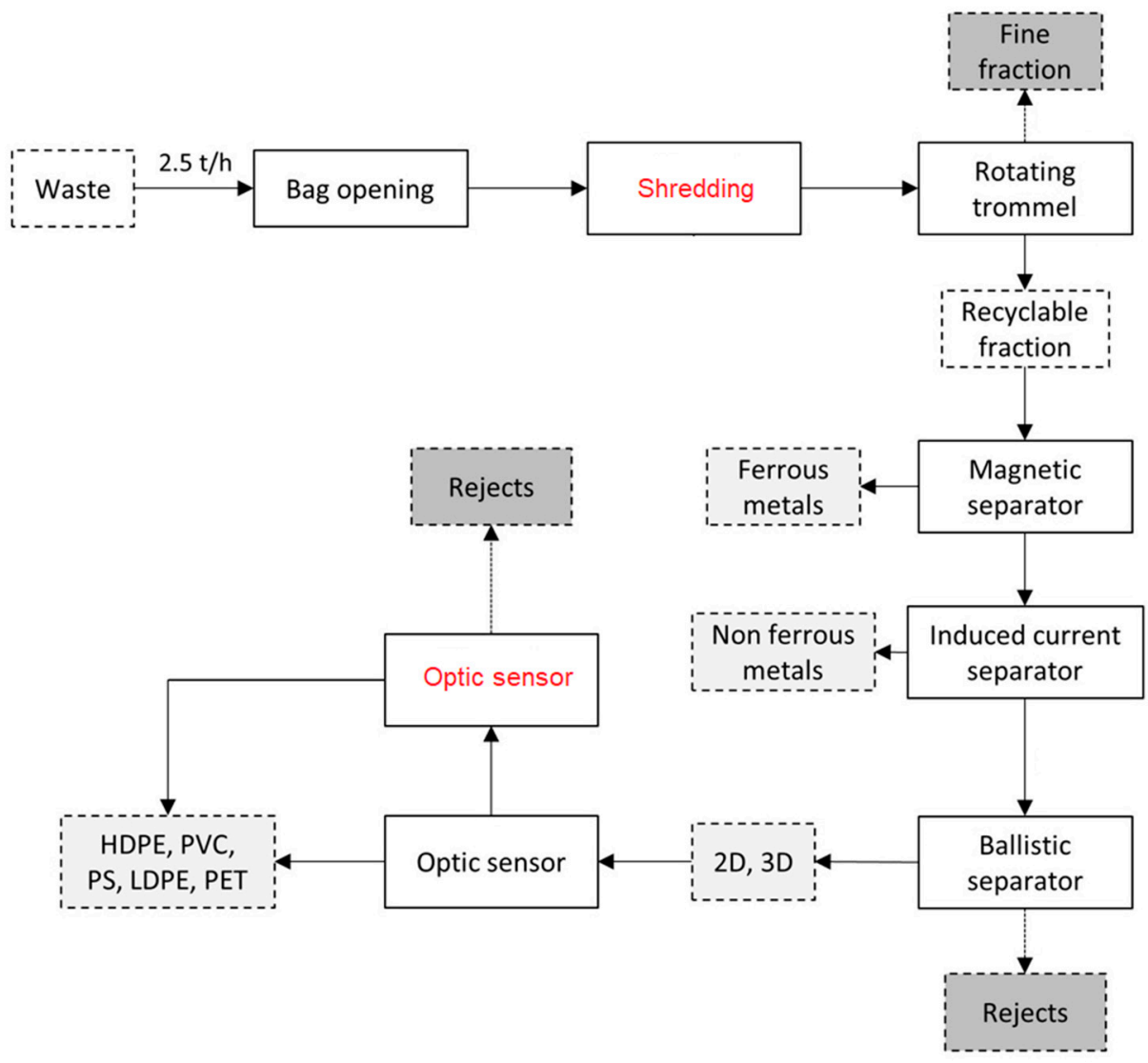

Figure 2. Structure of the MRF after modifications.

Table 4. Risk matrix of the shredding system [22].

\begin{tabular}{|c|c|c|c|c|c|c|c|c|c|c|c|}
\hline & \multirow[b]{2}{*}{ Assessed Risk } & \multicolumn{10}{|c|}{ Risks } \\
\hline & & $\begin{array}{l}\overline{0} \\
\frac{\pi}{00} \\
\frac{0}{0} \\
0\end{array}$ & 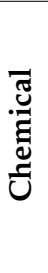 & $\begin{array}{l}\ddot{n} \\
\frac{0}{0}\end{array}$ & 龸 & 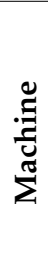 & 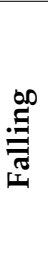 & 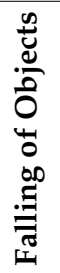 & $\frac{n}{3}$ & $\underbrace{\stackrel{ \pm}{ \pm}}_{\text {ț }}$ & $\stackrel{\leftrightarrows}{: ~}$ \\
\hline \multirow{5}{*}{ 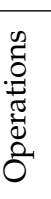 } & Waste charging & 2 & 4 & 9 & 4 & 9 & 2 & 3 & 2 & 4 & 2 \\
\hline & Shredding & 1 & 2 & 9 & 4 & 3 & 4 & 9 & 4 & 2 & 2 \\
\hline & Waste storage & 2 & 2 & 6 & 4 & 6 & 2 & 3 & 4 & 4 & 1 \\
\hline & Waste movement & 2 & 4 & 6 & 4 & 6 & 2 & 3 & 4 & 4 & 1 \\
\hline & Clean of the areas & 2 & 4 & 9 & 2 & 9 & 4 & 9 & 6 & 2 & 1 \\
\hline
\end{tabular}

Note: green $=$ acceptable; yellow $=$ low ; orange $=$ significant; red $=$ high .

Moreover, a second mechanical separation could be introduced at the end of the systems, after the last optic sensors. In this case, a good option could be the implementation of another optic separation. In this case, the main risk could be detected only by the clean of the areas and the movement of the rejects. The risk matrix is reported in Table 5 (modified from the original version, as the biological risk has been considered reduced for taking into account of the local context of high quality separation). Additionally, in this case, the risk is considerably reduced if compared with the manual separation (green classified risks are dominant, whilst in case of manual separation the green class results in only $31 \%$ of the evaluations). However, the system could have cons concerning the quality of the material 
selected and the limits of an optic separation device. Indeed, the introduction of this device could be more interesting in case of colored material, since it has difficulties in the separation of black materials.

Table 5. Risk matrix optical sensors [22].

\begin{tabular}{|c|c|c|c|c|c|c|c|c|}
\hline & \multirow[b]{2}{*}{ Assessed Risk } & \multicolumn{7}{|c|}{ Risks } \\
\hline & & $\begin{array}{l}\text { Jే } \\
.0 \\
\frac{0}{00} \\
\frac{0}{0} \\
0\end{array}$ & 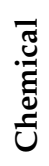 & $\begin{array}{l}\ddot{n} \\
\stackrel{0}{0} \\
z\end{array}$ & 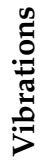 & 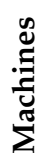 & $\frac{n}{3}$ & 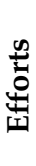 \\
\hline \multirow{4}{*}{ 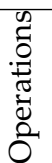 } & Optic separation & 2 & 1 & 1 & 1 & 2 & 2 & 1 \\
\hline & Waste charging & 2 & 1 & 1 & 1 & 2 & 4 & 1 \\
\hline & Waste movements & 2 & 1 & 1 & 2 & 4 & 2 & 2 \\
\hline & Clean of the areas & 2 & 1 & 1 & 2 & 4 & 4 & 1 \\
\hline
\end{tabular}

Note: green $=$ acceptable; yellow $=$ low; orange $=$ significant; red $=$ high

\subsection{Economic Comparison}

Comparing the manual separation and the mechanical separation from an economic perspective, it could be stated that the substitution suggested is not only relevant for reducing the risk, while also for the financial sustainability. Considering that an operator could select about $0.5 \mathrm{t} / \mathrm{h}$ of solid waste, at the first step not less than four operators are required, while at the end of the process is necessary one operator. With these five operators, another should be assumed for substituting the holidays and the illnesses. The cost of an operator in Italy, considering all the taxes, is about $€ 2500$ per month, for a total of $€ 150,000$ per year for a five-person team, which is equal to 1,500,000 in ten years. The cost of a shredder could be around $€ 25,000$ while the cost of an optical separation device is around $€ 150,000$. Adding $€ 20,000$ for maintenance and $€ 10,000$ of operation costs, in ten years the expenses are around $€ 625,000$. Therefore, comparing both expenses, in ten years the investment could be recovered according to this preliminary analysis.

\subsection{Change of Context}

Two important considerations concern the change of context:

- The behavior of the citizens can affect the biological risk (and not only) at the MRF; that depends on the skills of the population in avoiding putrescible materials in the light packaging waste stream. In well-organized contexts putrescible materials are source separated in a dedicated stream, according to the principles of waste management in the EU.

- The composition of Municipal Solid Waste can affect the risk at the MRF. e.g., in case of bad source separation of cans (cutting elements) the risk could be lower than the case of good behavior in separating. These aspects should be taken into account carefully when designing a MRF.

\section{Conclusions}

This article investigated the reduction of occupational risk substituting a manual with a mechanical separation in a MRF for light packaging. The analysis was developed referring to a small capacity facility. Considering the results obtained, the implementation of the mechanical separation could be interesting for reducing both the operational risk and the expenses. Concerning the risk, the classes of risk related to the substituted steps of treatment can be clearly reduced by the mechanization: no case of highest class remains after substitution of the manual treatments in the involved stages of processing. Concerning the expenses, the presented economic analysis, even if preliminary, is adequate to highlight that the manual approach is not compulsory in a MRF. Even if automatized, the risk in a MRF remains depending on the human behavior: a high-quality of source separation avoids the 
presence of putrescible materials in the concerned stream (the light packaging from SC), reducing the biological risk for the workers. The presented analysis refers to a context where SC has been optimized.

Author Contributions: All the authors contributed equally to the present work, according the following main roles: Conceptualization, M.R. and V.T.; Methodology, N.F.; Validation, E.M. and P.V.; Writing-Original Draft Preparation, N.F. and V.T.; Writing-Review \& Editing, E.C.R. and M.R.; Supervision, L.I.C. and E.C.R.

Funding: This research was funded by Lucian Blaga University of Sibiu research grants number [LBUS-IRG-2018-04].

Acknowledgments: The authors thank Federica De Vecchi and Pierangelo Reguzzoni for their previous collaboration that allowed having a starting point for the development of the present article.

Conflicts of Interest: The authors declare no conflict of interest.

\section{References and Notes}

1. EC-European Commission. Implementation of the Circular Economy Action Plan. Circular Economy Package. 2018. Available online: http://ec.europa.eu/environment/circular-economy/index_en.htm (accessed on 3 September 2018).

2. Rada, E.C.; Ragazzi, M.; Torretta, V.; Castagna, G.; Adami, L.; Cioca, L.I. Circular economy and waste to energy. AIP Conf. Proc. 2018, 1968, 030050. [CrossRef]

3. Park, S.; Lah, T.J. Same material different recycling standards: Comparing the municipal solid waste standards of the European Union, South Korea and the USA. Int. J. Environ. Waste Manag. 2018, 21, 80-93. [CrossRef]

4. Dijkgraaf, E.; Gradus, R. An EU Recycling Target: What Does the Dutch Evidence Tell Us? Environ. Resour. Econ. 2017, 68, 501-526. [CrossRef]

5. Gregson, N.; Crang, M.; Botticello, J.; Calestani, M.; Krzywoszynska, A. Doing the 'dirty work' of the green economy: Resource recovery and migrant labour in the EU. Eur. Urban Reg. Stud. 2016, 23, 541-555. [CrossRef]

6. Ciudin, R.; Isarie, C.; Cioca, L.; Petrescu, V.; Nederita, V.; Ranieri, E. Vacuum waste collection system for an historical city centre. UPB Sci. Bull. 2014, 76, 215-222.

7. Lakatos, E.S.; Cioca, L.I.; Dan, V.; Ciomos, A.O.; Crisan, O.A.; Barsan, G. Studies and investigation about the attitude towards sustainable production, consumption and waste generation in line with circular economy in Romania. Sustainability 2018, 10, 865. [CrossRef]

8. ISPRA-Istituto Superiore per la Protezione e la Ricerca Ambientale. Rapporto Rifiuti Urbani 2016; ISPRA: Rome, Italy, 2016. Available online: http:/ / www.isprambiente.gov.it/it/pubblicazioni/rapporti/rapportorifiuti-urbani-edizione-2016 (accessed on 3 September 2018). (In Italian)

9. Ragazzi, M.; Fedrizzi, S.; Rada, E.C.; Ionescu, G.; Ciudin, R.; Cioca, L.I. Experiencing Urban Mining in an Italian Municipality towards a Circular Economy vision. Energy Procedia 2017, 119, 192-200. [CrossRef]

10. Rada, E.C.; Zatelli, C.; Mattolin, P. Municipal solid waste selective collection and tourism. WIT Trans. Ecol. Environ. 2014, 180, 187-197. [CrossRef]

11. Ranieri, E.; Rada, E.C.; Ragazzi, M.; Masi, S.; Montanaro, C. Critical analysis of the integration of residual municipal solid waste incineration and selective collection in two Italian tourist areas. Waste Manag. Res. 2014, 32, 551-555. [CrossRef]

12. Rada, E.C.; Zatelli, C.; Cioca, L.I.; Torretta, V. Selective Collection Quality Index for Municipal Solid Waste Management. Sustainability 2018, 10, 257. [CrossRef]

13. Tantau, A.D.; Maassen, M.A.; Fratila, L. Models for analyzing the dependencies between indicators for a circular economy in the European Union. Sustainability 2018, 10, 2141. [CrossRef]

14. Morlok, J.; Schoenberger, H.; Styles, D.; Galvez-Martos, J.L.; Zeschmar-Lahl, B. The Impact of Pay-As-You-Throw Schemes on Municipal Solid Waste Management: The Exemplar Case of the County of Aschaffenburg, Germany. Resources 2017, 6, 8. [CrossRef]

15. MRF facilities in Italy. Available online: http://www.corepla.it/documenti/a6a80177-58a5-4353-a876dc279e8ce855/Anagrafica+CSS+giu17.pdf (accessed on 3 September 2018).

16. Moussiopoulos, N. Investigation of the occupational health and safety conditions in Hellenic solid waste management facilities and assessment of the in-situ hazard level. Saf. Sci. 2017, 96, 192-197. [CrossRef] 
17. Battaglia, M.; Passetti, E.; Frey, M. Occupational health and safety management in municipal waste companies: A note on the Italian sector. Saf. Sci. 2015, 72, 55-65. [CrossRef]

18. Bastani, M.; Moore, D.E.; Celik, N. Case studies on quantification of occupational health risks for solid waste workers in Floridian counties. In Proceedings of the IIE Annual Conference and Expo, Montreal, QC, Canada, 31 May-3 June 2014; pp. 633-642.

19. Rubio-Romero, J.C.; del Carmen Pardo-Ferreira, M.; De la Varga-Salto, J.; Galindo-Reyes, F. Composite leading indicator to assess the resilience engineering in occupational health \& safety in municipal solid waste management companies. Saf. Sci. 2018, 108, 161-172. [CrossRef]

20. La sicurezza per gli operatori degli impianti di trattamento e di stoccaggio dei rifiuti solidi urbani. Available online: https:/ / www.inail.it/cs/internet/comunicazione/pubblicazioni/catalogo-generale/la-sicurezzaper-gli-operatori-degli-impianti.html (accessed on 20 November 2018). (In Italian)

21. Sorting and Processing of Light Weight Packaging Waste. Available online: https:/ / www.retech-germany. net/ (accessed on 3 September 2018).

22. De Vecchi, F. Definizione Delle Linee Guida per la Gestione di un Impianto di Selezione di Imballaggi Leggeri in Italia. Master's Thesis, University of Trento, Trento, Italy, 2014-2015. (In Italian)

23. Italian single text on health and safety at work. D.lgs. 9 April 2008, n. 81, coordinated with the D.Lgs. 3 August 2009, n. 106: Italian Gazzetta Ufficiale n. 101 of 30 April 2008-Annex n. 108 and Integrative Decree on Gazzetta Ufficiale n. 180 of 05 August 2009, Annex n. 142/L. Available online: http:/ /www. gazzettaufficiale.itg. (accessed on 3 September 2018). (In Italian)

24. Ragaert, K.; Delva, L.; Van Geem, K. Mechanical and chemical recycling of solid plastic waste. Waste Manag. 2017, 69, 24-58. [CrossRef] [PubMed]

25. Gu, F.; Guob, J.; Zhang, W.; Summers, P.A.; Hall, P. From waste plastics to industrial raw materials: A life cycle assessment of mechanical plastic recycling practice based on a real-world case study. Sci. Total. Environ. 2017, 601-602, 1192-1207. [CrossRef]

26. Lupo, E.; Moroni, M.; La Marca, F.; Fulco, S.; Pinzi, V. Investigation on an innovative technology for wet separation of plastic wastes. Waste Manag. 2016, 51, 3-12. [CrossRef]

27. Martínez Urreaga, J.; Gonzalez-Sanchez, C.; Martínez-Aguirre, A.; Fonseca-Valero, C.; Acosta, J.; de la Orden, M.U. Sustainable eco-composites obtained from agricultural and urban waste plastic blends and residual cellulose fibers. J. Clean. Prod. 2015, 108, 377-384. [CrossRef]

28. Cossu, R.; Garbo, F.; Girotto, F.; Simion, F.; Pivato, A. PLASMIX management: LCA of six possible scenarios. Waste Manag. 2017, 69, 567-576. [CrossRef]

29. Schaefer, C.E.; Kupwade-Patil, K.; Ortega, M.; Soriano, C.; Büyüköztürk, O.; White, A.E.; Short, M.P. Irradiated recycled plastic as a concrete additive for improved chemo-mechanical properties and lower carbon footprint. Waste Manag. 2018, 71, 426-439. [CrossRef] [PubMed] 